\title{
Age and Second Language Acquisition and Processing: A Selective Overview
}

\author{
David Birdsong \\ University of Texas at Austin
}

\begin{abstract}
This article provides a selective overview of theoretical issues and empirical findings relating to the question of age and second language acquisition (L2A). Both behavioral and brain-based data are discussed in the contexts of neurocognitive aging and cognitive neurofunction in the mature individual. Moving beyond the classical notion of "deficient" L2 processing and acquisition, we consider the complementary question of learner potential in postadolescent L2A.
\end{abstract}

The outcome of second language acquisition (L2A) among adults is demonstrably different in many respects from the outcome of first language acquisition (L1A) among children. Departing from this basic observation, researchers attempt to understand the various sources of age-related effects in L2A.

The present article is an overview of facts and theoretical issues concerning age and L2A. This contribution considers both behavioral data and brain-based processing data. The review includes findings and controversies in the areas of neurocognitive development and aging, and cognitive neurofunction in the mature brain.

A comprehensive treatment of the facts and issues is not possible in the space available. It is hoped, nevertheless, that this selective offering provides useful scaffolding for other articles in

Correspondence concerning this article should be addressed to David Birdsong, Department of French and Italian, University of Texas, 1 University Station B7600, Austin, TX 78712-0224. Internet: birdsong@ ccwf.cc.utexas.edu 
this volume that examine cognitive and neural aspects of L2 use and acquisition.

\section{Background and Terminology}

Over the past 20 or so years, a great deal of empirical research on the age question in L2A has focused on the end state of L2A, not on rates of attainment or on stages of L2 development. The developmental literature and comparative rate (adult vs. child) literature are certainly not without interest, and overviews of this research can be found in Klein (1995), MarinovaTodd, Marshall, and Snow (2000), and Pienemann, Di Biase, Kawaguchi, and Hakansson (2005).

However, it is essential that the end state receive its share of attention, because it is evidence from the end state that determines the upper limits of L2 attainment. Knowing the potential of the learner permits inferences about the nature of putative constraints on acquisition, including their relative strength and ultimate impact on learning (see Long, 1990, pp. 253-259). Accordingly, the end state is the focus of the present article. Both as a matter of logic and as a matter of theoretic adequacy, it is important to recognize that when comparing L1A and L2A, a superficial difference in ends does not necessarily imply an underlying difference in means. Nor does similarity of ends/products necessarily imply similar means/processes. Thus, for example, with respect to the question of Universal Grammar's (UG) mediating role in L2A, we understand that nativelikeness at the L2A end state does not always imply access to UG. ${ }^{1}$ By the same token, it is clear that nonnativelike linguistic behaviors are not necessarily evidence of lack of access to UG. Researchers must be wary of linking end-state differences in L1A and L2A exclusively to a loss of general learning ability or exclusively to some erosion of any putative mechanism(s) responsible for successful L1A. Thus, linkages between product and process are to be established only with due caution. 
In the literature, the terms end state, final state, steady state, ultimate attainment, and asymptote are used more or less interchangeably to refer to the outcome of L2A. Note that "ultimate attainment" has occasionally and erroneously been used as a synonym for nativelike proficiency. However, the term properly refers to the final product of L2A, whether this be nativelike attainment or any other outcome. For divergent views of the construct of "end state" in L2A, see Larsen-Freeman (2005) and White (2003). For discussion of operationalizing the L2A end state, see Birdsong (2004).

Researchers have explored several biographical variables that might be predictive of L2A outcomes. Age of acquisition (AoA) is understood as the age at which learners are immersed in the L2 context, typically as immigrants. This landmark is distinct from age of first exposure (AoE), which can occur in a formal schooling environment, visits to the L2 country, extended contact with relatives who are L2 speakers, and so forth. Researchers tend to equate the terms late L2A, postadolescent L2A, and postpubertal L2A; these are typically operationalized as AoA of $>12$ years. Length of residence (LoR) refers to the amount of time spent immersed in the L2 context. Because residence does not guarantee exposure to and use of the L2, researchers quantify the actual amount of contact L2 learners have with the L2 (in spoken and written modalities) and the relative use of the L 1 versus the L2 in day-to-day activities. Other experiential variables include amount of formal training in the L2 as a foreign language (e.g., grammar courses, corrective phonetics) as well as amount of exposure to the L2 in so-called content courses, where nonnatives are enrolled in high school, vocational, or university classes in the L2 country.

Endogenous variables of interest to L2A researchers include the following: motivation (with several subtypes relating to outcome, e.g., motivation to pass for a native, motivation to acquire lexico-grammatical accuracy), psycho-social integration with the L2 culture, aptitude (with several presumed components, 
including imitative ability, working memory capacity, metalinguistic awareness, etc.), and learning styles and strategies. These are understood to be continuous, not all-or-nothing, variables. For overviews of these variables, see Dörnyei and Skehan (2003) and Doughty (2003).

\section{AoA and L2 Ultimate Attainment}

It is widely recognized that AoA is predictive of $\mathrm{L} 2 \mathrm{~A}$ outcomes, in the simple sense that AoA is observed to significantly correlate negatively with attained L2 proficiency at the end state. This conclusion is based on the results of more than two dozen experimental studies; see Birdsong (2005) and DeKeyser and Larson-Hall (2005) for overviews. The areas of language most commonly investigated are morphosyntax and pronunciation. Typically, morphosyntax errors in production or grammaticality judgments increase with advancing AoA, as does degree of judged nonnative accent.

Across many studies that examine AoA and other factors that might be related to L2 success, it has emerged that, of all the above-mentioned experiential variables, AoA is reliably the strongest predictor of ultimate attainment. This is not to say that other variables, indeed some that are confounded with AoA, are not predictive. In many cases, variables such as LoR and AoE are controlled statistically or included as factors in the experimental design.

\section{The Age Function}

From the actual behavioral data, a recurrent finding is that a linear function captures the relationship between AoA and outcome over the span of AoA (i.e., when considering aggregate data from both early- and late-AoA subjects). In 10 surveyed studies, the range of correlations is .45 to .77 , with a median of about .64 (all absolute values). ${ }^{2}$ The slope of the age function varies (i.e., it is steeper or shallower) as a function of such factors as L1-L2 
pairing, amount of L2 use, task, education in the L2, and so on. It is also not surprising to find, given what is known about learning and cognitive performance over the life span (Schaie, 1994; Weinert \& Perner, 1996), that there is less intersubject variation in outcome among early arrivals than among late arrivals.

When data from early- and late-AoA subjects are disaggregated, inconsistent results are obtained, producing a clouded picture of the timing and geometry of the age function. For example, DeKeyser (2000) studied 57 Hungarian L1 English L2 subjects with AoA ranging from 1 to 40 years, all with at least 10 years of U.S. residence. On a grammaticality judgment test using some items from Johnson and Newport (1989) along with some novel items, a significant correlation of AoA with scores was obtained $(r=-.63, p<.001)$. However, when DeKeyser broke out the data by early- and late-arriving subjects, neither set of data yielded a significant correlation with AoA (early arrivals $n=15, r=-.24$, $\mathrm{ns}$; late arrivals $n=42, \mathrm{r}=-.04, \mathrm{~ns}$ ).

Another illustration of the disparate results of analyses of aggregate versus disaggregated data is seen in the comparison of the results of Johnson and Newport (1989) and Birdsong and Molis (2001). Johnson and Newport looked at accuracy on a 276item grammaticality judgment by a group of Chinese and Korean natives $(n=46)$ with English as their L2. The Birdsong and Molis study was a strict replication of Johnson and Newport, but in this case, the subjects were Spanish natives $(n=61)$. Over all subjects and AoAs, Johnson and Newport found a strong linear relationship between AoA and accuracy $(r=-.77, p<.01)$. This finding was reproduced by Birdsong and Molis $(r=-.77, p<$ .0001). However, when the subjects were divided into AoA groups of $\leq 16$ years and $>16$ years, the analyses produced divergent results. Figure 1 represents these differences.

The pattern of results seen in Johnson and Newport (1989) is a decline in scores with increasing AoA for early arrivals $(r=$ $-.87, p<.01)$ and an essentially random distribution of scores for the older-arriving group $(r=-.16, \mathrm{~ns})$. A quite different pattern was obtained by Birdsong and Molis (2001). For early arrivals, 


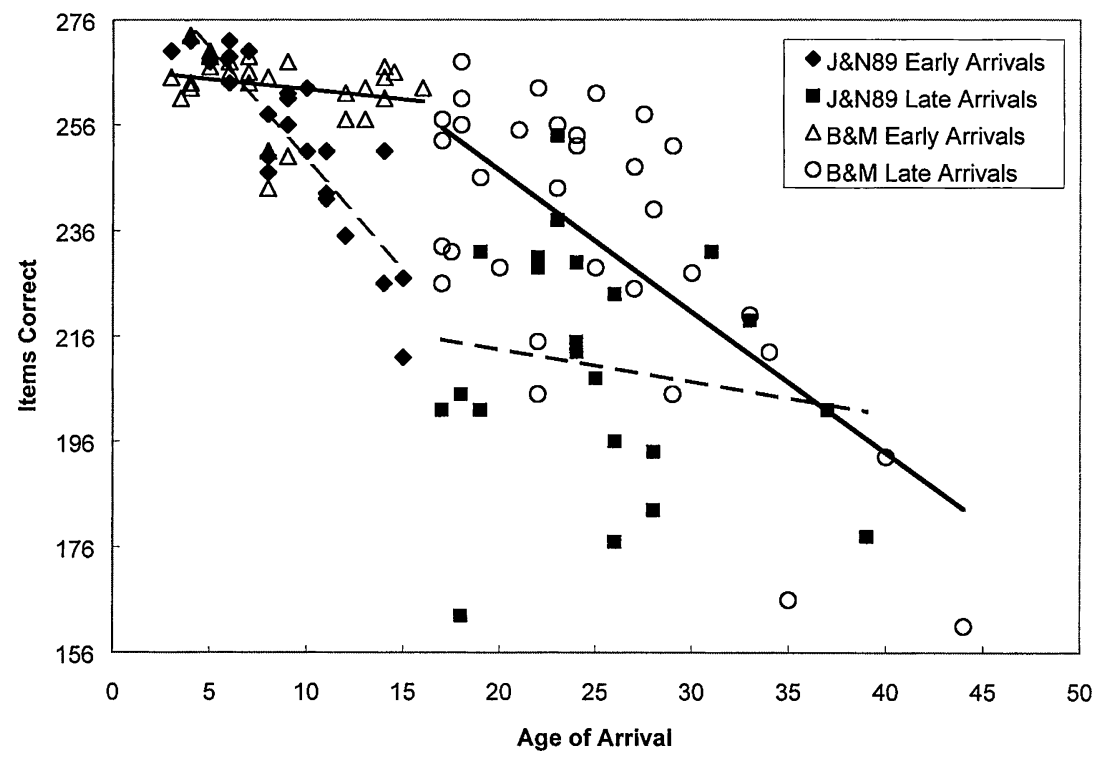

Figure 1. Plot of accuracy over AoA from Birdsong and Molis (2001, p. 240). Solid regression lines are fit to the Birdsong and Molis data; dashed lines are fit to the Johnson and Newport (1989) data. Early and late AoA groups are divided at 16 years.

the correlation of scores with age is not significant $(r=-.24, p=$ .22 ), as this subgroup performed at ceiling. For late arrivals, the correlation is strongly negative $(r=.69, p<.0001)$.

In a reexamination of the Johnson and Newport (1989) data, Bialystok and Hakuta (1994) moved the cutoff point separating early- and late-arriving groups to 20 years. For late learners, the subsequent correlation reached significance $(r=-.50, p<.05)$. Birdsong and Molis (2001) conducted a similar reanalysis of their data, placing the cutoff at various ages between 15 years and 27.5 years; all correlations reached significance.

The meta-analysis by Birdsong (2005) of L2 end-state morphosyntactic and pronunciation behavioral research arrives at three main conclusions: (a) In all analyses of pooled data from early and late arrivals, age effects persist indefinitely across the span of surveyed AoA (i.e., they are not confined to a 
circumscribed period); (b) In analyses of disaggregated samples (and in studies that look only at late AoA), most studies find significant AoA effects for the late learners, indicating postmaturational declines in attainment; (c) in analyses of early-arrival data alone, AoA effects are inconsistent: Some are flat, some are random, and some are monotonically declining.

\section{Do Observed AoA Effects Suggest a Maturationally Based Critical Period?}

We can now take a step back and consider whether observed AoA effects can be interpreted as critical period effects. ${ }^{3}$ If what we are dealing with is in fact a period, the age effects observed in the data must be confined to a finite time span; see Bornstein (1989) for a further discussion of characteristics of a critical period. Moreover, if the effects are maturational in nature, then the age function prior to the end of maturation should look different from the age function after the end of maturation.

Taken together, the requirement of finite age effects and a discontinuity in the age function synchronized with the end of maturation permute into three basic patterns (see Figure 2). One is a stretched " $\mathrm{"}$ " or hockey stick shape, with age-related declines ceasing at a point of articulation that coincides with the end of maturation. The second is an upside-down mirror image of the stretched "L," resembling a stretched "7." The flat portion at the top left of the image is the period where success is guaranteed. A third possibility, laid out by Johnson and Newport (1989) and expanded by Pinker (1994), specifies a causal role of brain

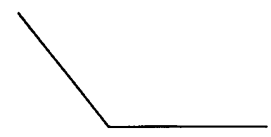

A

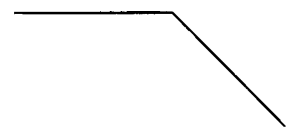

B

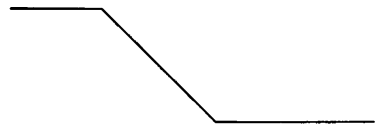

C

Figure 2. Three patterns of bounded age effects: (A) stretched "L" shape; (B) stretched "7" shape; (C) stretched "Z" shape. 
maturation in L2A age effects, with the end of age effects synchronized with the completion of brain maturation. This version combines features of the first two possibilities to produce the image of a stretched "Z." The function begins with a period of ceiling effects, followed by a decline that ceases at the end of maturation, after which the age function flattens and no further age effects are seen.

Let us consider the third possibility first. The stretched "Z" shape (Figure 2C) includes two finite periods. At the upper left portion of the image, where performance is at ceiling, we indeed observe a bounded period, which is actually a period during which age effects are absent, as there is no downward slope in the age function. The next segment is a bounded downward slope; the age effect begins prepubertally and ends at the completion of maturation. The third segment, which is unbounded, captures the hypothesized bottoming out or flattening of the age function. Johnson and Newport (1989) purport to have produced findings consistent with the timing and geometric features just described. However, instead of an orderly array of scores parallel to the $x$ axis-that is, the hypothesized floor effect-one finds a random dispersion of points. In other words, the crucial flattening feature of the function, whose beginning should coincide with the end of maturation, is in fact not present in the data.

Moreover, as mentioned earlier, if following Bialystok and Hakuta (1994), one moves the cutoff point to 20 years, the latearrivals data in Johnson and Newport (1989) start to look a bit more orderly. The result of the ensuing analysis is neither a random distribution nor a floor effect, but a significant negative correlation of AoA and performance for the late-arriving group.

The stretched "L" or hockey-stick representation (Figure 2A) incorporates a sloping segment on the left that would satisfy the requirement of a bounded period during which AoA is negatively correlated with outcomes. It also contains a flattened segment, the beginning of which coincides with the end of maturation. A review of the literature (see Birdsong, 2005; DeKeyser \& Larson-Hall, 2005) reveals that several analyses of disaggregated 
data show prematurational declines-the left portion of the stretched L. However, for later learners (i.e., those whose performance would be represented by the right segment of the stretched "L"), there is no evidence of a flat function or floor effect. Instead, for late-learner groups, there is either a random array of scores (e.g., DeKeyser, 2000; Patkowski, 1990) or a persistent decline in performance with increasing AoA (e.g., Bialystok \& Miller, 1999; Birdsong, 1992). Returning to Figure 2A, we note that the appearance of a stretched "L" shape (i.e., the two rightward segments of the "Z") is obtained for the Johnson and Newport (1989) data when linear functions are applied separately to early- and late-arrival data. A systematic performance decline over AoA is indeed observed for early arrivals $(r=-.87)$. However, as we saw earlier, for late arrivals, a flat segment is a misleading representation of the correlation coefficient in this instance $(r=-.16)$, as the best-fitting near-horizontal regression line actually goes through a random array of scores, not through an orderly set of points that are parallel to the $x$-axis.

The final scenario by which age effects would be considered critical period effects is the mirror image of the one just discussed, a stretched "7" or upside-down hockey stick shape with the "blade" at the top left (Figure 2B). This is an unconventional, although often implicitly invoked, notion of a critical period function (see Birdsong, 2005, for discussion of conventional and unconventional conceptions; based on Bornstein, 1989). The leftmost part of the function is flat, with performance at ceiling. On the right portion of the image, the age gradient (i.e., the decline in ultimate attainment with advancing AoA) is not bounded. What is bounded is the left segment of the image, the period of peak attainment, which is often referred to as a "window of opportunity"- the temporal span during which sensitivity or learning potential is at its highest and full attainment is guaranteed. Such a period has been observed in at least one study: Birdsong and Molis (2001). ${ }^{4}$ As seen in Figure 1, a roughly flat function at ceiling is generated by the performance of the early-arriving AoA group of Spanish L1 speakers. This "age noneffect" is confined to a limited span, thus satisfying 
the geometric criterion and corresponding to the unconventional "window of opportunity" version of the critical period. However, because of the apparent duration of the window of opportunity, the temporal features do not conform to a maturational account of AoA effects. For their L2 learners' results, Birdsong and Molis (pp. 241-242) conducted a series of post hoc piecewise regression analyses that included the inflection point (i.e., the terminus of the period) as a free parameter. Under these conditions, the bestfitting function placed the end of the ceiling period, and thus the beginning of the decline, at 27.5 years. In other words, the period of peak performance extends 10 or more years beyond the end of maturation. Thus, although the Birdsong and Molis results reveal a stretched "7" shape and its circumscribed period of full attainment, the temporal parameters do not mesh with a maturational-effects account of L2 ultimate attainment.

\section{Divergent Conceptualizations of "Critical Period"}

Singleton (2005) examined several proposals for the timing of the "end of the critical period." In most cases, these proposals made reference to the end of the period of peak sensitivity; that is, they invoked the "window of opportunity" notion of critical period. In the studies that Singleton surveyed, hypothesized beginnings of declines ranged from near birth to late adolescence. Some proposals made distinct timing claims for phonetics/phonology versus other areas of linguistic knowledge and performance. Such so-called "multiple critical period" accounts of attainment in various language domains were advanced by Long (1990) and Seliger (1978) for the L2 context and are consistent with current neurobiological thinking about critical periods in other contexts (Knudsen, 2004).

The proposals of Johnson and Newport (1989), Lenneberg (1967), Long (1990), Pinker (1994), Scovel (1988), and Seliger (1978) signaled changes that occur around puberty. Significantly, in some cases, this maturational milestone is thought to be the point at which declines in performance begin (i.e., the 
unconventional notion of critical period), and in other cases, this maturational milestone is thought to be the point at which performance declines cease (the conventional notion). Thus, a serious conceptual issue confronts proponents of a maturational account of constraints on L2A attainment: Does maturation determine the beginning of age effects or the end of age effects?

Empirically, neither account of the timing of maturational effects fares very well. As discussed earlier, it is now understood (e.g., Birdsong, 2005; Hyltenstam \& Abrahamsson, 2003) that the behavioral data are generally inconsistent with either a period of peak sensitivity whose end coincides with the end of maturation or with a leveling off of sensitivity whose beginning coincides with the end of maturation. For additional commentary on the timing of age effects, see Moyer (1999).

\section{Incidence of Nativelike Attainment in Late L2A}

Like the facts about the age function, the facts relating to nativelike attainment in L2A do not lend themselves to simple generalization. Moreover, as was the case with the age function, the interpretation of these facts is not without controversy.

Historically, research in L2A has been guided by what has been termed the deficit model. Characterizing the end state of L2A as a "lack of success," research in this tradition looks to explain the "near-universal failure" of adults to reach attainment comparable to that observed in L1A (Bley-Vroman, 1989). The prevailing view was that nativelikeness, if ever observed, was so rare as to be of no relevance to L2A theory (e.g., Bley-Vroman; Selinker, 1972). Estimates of a $0-5 \%$ incidence of nativelikeness were more a matter of guesswork than experimentation and might have referred to a population that included foreign language learners and others who were not at the L2A end state. More recently, however, a number of studies have targeted immigrants with sufficient LoR and contact with natives to qualify for end-state status and have scrupulously attempted to ascertain the rate of nativelikeness in the sample. The findings of these 
studies suggest that nativelikeness in late L2A is not typical, but neither is it exceedingly rare.

More than 20 studies have reported the rate of nativelikeness among late ( $\mathrm{AoA} \geq 12$ years) L2A learners. In these studies, the incidence of nativelikeness ranges from $0 \%$ to $45.5 \%$. Higher rates of nativelikeness in the area of morphosyntax are associated with certain L1-L2 pairings (e.g., Cranshaw, 1997), with increased L2 use (e.g., Flege, Yeni-Komshian, \& Liu, 1999), and with L2 dominance (e.g., Flege, MacKay, \& Piske, 2002). In the area of pronunciation, those learners who are taken for natives by native judges tend to be those with high levels of $\mathrm{L} 2$ practice, motivation to sound like a native, and L2 phonetic training (e.g., Bongaerts, 1999).

Anecdotal evidence, along with some research, suggests that nativelikeness is attested less often in the domain of pronunciation than in other performance domains. However, nativelike pronunciation is not impossible, as studies by Birdsong (2003) and Bongaerts and colleagues (see Bongaerts, 1999, for summaries of their studies) have shown. The perceptual abilities underlying unaccented L2 pronunciation have proved to be amenable to training in some studies (e.g., Bradlow, Pisoni, Akahane-Yamada, \& Tohkura, 1997; McCandliss, Fiez, Protopapas, Conway, \& McClelland, 2002; McClelland, Fiez, \& McCandliss, 2002) but resistant to training in others (e.g., Takagi, 2002; see Darcy, Peperkamp, \& Dupoux, in press, for an overview).

\section{Domains of Nativelikeness}

There exists a widespread belief (Hyltenstam \& Abrahamsson, 2000, 2003; Long, 1990; Scovel, 1988) that nativelike attainment by late L2 learners, if observed at all, will be confined to one or a few tasks and that an individual will not display nativelikeness across a variety of linguistic behaviors (or experimental performances). The coinage "Joseph Conrad effect" captures this notion. However, recent work suggests that the attainment of broad nativelikeness among late L2 learners is in fact possible. In 
a study of end-state L2 English acquisition, Marinova-Todd (2003) recruited 30 late learners $(\mathrm{AoA}>16$ years; mean $=11$ years $)$ with at least 5 years' residence (mean $=11$ years) in an Englishspeaking country. These subjects had been informally screened for high English proficiency and, like the 30 native controls, were college educated. Nine tasks targeted an array of linguistic performance. Two tasks related to pronunciation, one for spontaneous speech and one for read-alouds; three tasks tested morphosyntactic accuracy in both online and offline performance; two tasks probed lexical knowledge in oral descriptions; and two tasks involved language use in narrative and discourse. Of the 30 late learners, 3 performed to nativelike criteria across all nine tasks. Six others were indistinguishable from natives on seven tasks. The results of this study are of particular interest because the performances tested included not only the core areas of grammar and pronunciation but also lexical diversity and narrative and discourse competence. Moreover, some of the tasks used by Marinova-Todd did not involve reflection and metalinguistic analysis, thus muting the argument that nonnativelikeness will inevitably be ferreted out in spontaneous language use (Hyltenstam \& Abrahamsson, 2000, 2003). See Birdsong (to appear) and Ioup, Boustagui, El Tigi, and Moselle (1994) for additional evidence of broad nativelikeness in late L2A. Where nativelikeness is perhaps least likely to be observed is in certain domains of language processing. Differences between highly proficient late L2 learners and monolingual natives have been noted in the areas of lexical retrieval, structural ambiguity resolution, and detection of acoustic distinctions in the areas of syllable stress, consonant voicing, and vowel length (e.g., Clahsen \& Felser, 2006; Dussias, 2004; Dupoux \& Peperkamp, 2002; Papadopoulou \& Clahsen, 2004). The observed behavioral differences appear to be both quantitative (speed, accuracy) and qualitative (parsing in a structurally shallow manner; mishearing segments) in nature. Other types of sentence processing difference between natives and learners are revealed in event-related potential (ERP) and eye-tracking studies; see Frenck-Mestre (2005) for a review. 


\section{Use of Evidence of (Non-)Nativelikeness}

There is ongoing discussion about the relevance to L2A theory of behavioral evidence showing end-state nativelikeness and nonnativelikeness. Should researchers dig around for any soupçon of nonnativelikeness and declare this to be proof that learning mechanisms are rendered defective by aging? Consider the use of a nonnative lexical item-say, an exclamation in a moment of passion or pain. Does this departure from nativelikeness constitute evidence of defective L2 learning?

Now consider small quantitative differences between the L2 and native L1 (e.g., shorter-than-native-norm voice onset time [VOT] values averaged over subjects). In bilingualism, L2 VOT values tend to move toward L1 VOT values; at the same time, L1 VOT values of bilinguals move toward L2 values (Flege \& Hillenbrand, 1984; Mack, Bott, \& Boronat, 1995). L2 effects in the L1 have been observed in such diverse domains as collocations (Laufer, 2003), middle-voice constructions (Balcom, 2003), syntactic processing (Cook, Iarossi, Stellakis, \& Tokumaru, 2003), and lexical decision (Van Hell \& Dijkstra, 2002). Rather than invoke deficiencies in learning (which could not apply to changes in the L1), it is more reasonable to argue that minor quantitative departures from monolingual values are artifacts of the nature of bilingualism, wherein each language affects the other and neither is identical to that of a monolingual. For further discussion, see Cook (2002), Flege (2002), and Grosjean (1989).

\section{L2 Dominance}

To conclude this consideration of nativelikeness in late L2A, I would like to suggest that investigations of the upper limits of attainment in late L2A could profit by targeting an underrepresented group, namely late L2 learners who are L2-dominant. Flege et al. (2002) presented an illustration of the possible benefits of such investigations. The researchers looked at the English pronunciation of three groups of Italian 
L1/English L2 bilinguals: L1-dominants, balanced bilinguals, and L2-dominants. They found that both L1-dominants and balanced bilinguals spoke with detectable accents, whereas the pronunciation of L2-dominant bilinguals was indistinguishable from that of native controls. Flege et al. speculated that, in the area of pronunciation at least, L2-dominants are less likely to be subject to interference effects from the L1. Whether or not this speculation proves tenable, researchers should recognize the possibility that data from L1-dominants, high-L2-proficients, and even balanced bilinguals might not give the full picture of the capacities of late L2 learners. ${ }^{5}$

To take the discussion of L2 dominance to a logical extreme, consider the case of the adoptees studied by Pallier et al. (2003). These eight individuals were removed from their native Korea at ages ranging from 3 to 8 years and were placed in homes in the Paris area. With no subsequent contact with Korean into their adult years, the adoptees' L2 (French) became their dominant language. Behavioral measures revealed no trace of residual Korean knowledge, and functional magnetic resonance imaging (fMRI) scans showed no specific activation when listening to Korean. Informal measures of their French speaking showed that the Korean adoptees behaved like French natives, and they performed like native French speakers on formal tests of French grammatical knowledge as well (Ventureyra, 2005). For determining the upper limits of L2A as a function of AoA, it would potentially be revealing to study larger numbers of such individuals, covering a larger range of age of adoption. Under such a design, the confounding effects of L1 representational entrenchment (on L1 entrenchment, see Kuhl, 2000; MacWhinney, 2005a) and L1 use would be minimized.

\section{Age and Nativelikeness in Brain-Based Measures}

As a complement to linguistic and metalinguistic data, brain-based evidence illuminates important dimensions of the question of age and L2A. A number of recent reviews gave more 
breadth and depth to discussion of relevant research than space permits here (e.g., Abutalebi, Cappa, \& Perani, 2005; Indefrey, this volume; Stowe \& Sabourin, 2005). See also Green (2005) and Paradis $(2004,2005)$ for discussions of the limitations of localization research using imaging techniques.

\section{Comparing L1 Processing and L2 Processing}

The basic research issue addressed in this area of cognitive neuroscience is whether processing in the L2 is accomplished in the same way as processing in the L1. The degree of observed similarity hinges on three principal factors: the age at which L2 acquisition is begun, the level of L2 proficiency, and the type of task demanded of the subjects. As one would expect with any complex cognitive activity, some of the most revealing results relate to interactions among these factors.

When comparing L1 and L2 processing, we might be referring to the psychology of cognition (e.g., automatic vs. controlled processes; implicit vs. explicit knowledge), the nature of mental representations (e.g., symbolic vs. subsymbolic representations; encapsulated vs. distributed representations), the general area of the brain that is activated (e.g., involvement of cortical vs. subcortical regions; left hemisphere vs. right hemisphere), or, within a given region of the brain, the particular neuronal circuits engaged in language processing.

AoA and Proficiency: Imaging Studies. Early research (e.g., Kim, Relkin, Lee, \& Hirsch, 1997) showed cortical activation differences between late and early bilinguals in L2 production tasks. It was tempting to conclude from these findings that later AoA results in nonnativelike brain activity patterns. However, this conclusion is not supported in subsequent investigations that have controlled for or manipulated the factor of L2 proficiency.

In studies of production, it is L2 proficiency level, not AoA, that emerges as the strongest predictor of degree of similarity between late learners and monolingual natives. This generalization must be qualified, however, as the degree of similarity varies 
from study to study. Moreover, what is meant by "production" is also quite variable, with tasks ranging from word repetition (Klein, Zatorre, Milner, Meyer, \& Evans, 1994), to (typically cued) word generation (Chee, Tan, \& Thiel, 1999; Klein et al., 1995), to sentence generation (Kim et al., 1997), to cognate and noncognate naming (De Bleser et al., 2003). Finally, from study to study, there are exposure differences and degree of proficiency differences that make comparisons and generalizations difficult.

In comprehension studies (of which there are relatively few), similar issues of incommensurability must be taken into account. Still, a coherent pattern of sorts emerges. For story listening tasks, two studies (Perani et al., 1996 [PET; positron-emission tomography]; Dehaene et al., 1997 [fMRI]) found differential activation between natives and low-proficient late learners. However, when Perani et al. (1998) compared high-proficiency late and early bilinguals on story listening (PET), overlapping patterns of brain activity were found.

Two fMRI investigations involving comprehension, then judgment, are worthy of note. Chee, Hon, Lee, and Soon's (2001) fMRI study of high- and low-proficiency bilinguals found that highly proficient subjects (AoA $\geq 12$ years) had relatively reduced brain activity in left prefrontal and parietal areas. The fMRI study of Wartenburger et al. (2003) involved semantic and grammar judgments by three groups of Italian-German bilinguals divided by AoA and proficiency (early acquisition/high proficiency; late acquisition/high proficiency; late acquisition/low proficiency). Activation for grammar judgments in the L2 was found to be related to AoA: The two high-proficiency groups with different AoAs showed different activations, the activations being more extensive across Broca's and other areas for the later learners. However, the authors point out that some differences might have been related to proficiency, as the nominally equal proficiency groups actually differed in grammaticality judgment accuracy. On the L2 semantic judgment task, similar activations were found for early and late high-proficients (i.e., irrespective of the AoA difference among the groups). Comparisons of L1 processing versus L2 processing 
were also carried out in within-group analyses. On the grammatical task, for both late-acquiring groups (i.e., both low and high proficiency), there was more extensive activation in Broca's and subcortical regions in L2 processing than in L1 processing. On the semantic task, the early acquisition/high-proficiency group did not exhibit differences in processing the L1 versus the L2. However, on this task, both of the late-acquiring groups showed greater bilateral activation in inferior frontal areas for L2 versus L1 processing.

Studies of word-level meaning and reference (Chee et al., 2000; Ding et al., 2003; Xue, Dong, Jin, Zhang, \& Wang, 2004) have shown similarities in areas of activation in L1 and L2. In the case of Xue et al. (2004), where subjects were asked to judge whether pairs of words were related, relatively late Chinese learners of English (age of exposure between 8 and 10) with rather low proficiency (subjects had had 2 years of English study and no other exposure or practice) showed activations in both L1 and L2 in the fusiform gyrus, Broca's area, and left parietal lobe.

Although there is a general congruence of brain areas activated in the L1 and L2 by proficient late bilinguals, the degree of activation might be different. Specifically, more neuronal activity in a given area is sometimes seen in L2 versus L1 processing, as indicated either by more voxels in a given area being activated or by more signal change for the same voxels. This pattern has been observed for early bilinguals as well as late bilinguals. These indexes correspond to increased neural activity in a specified area, and the extra activity could be viewed as evidence that the L2 is being processed with more effort than the L1 (Stowe \& Sabourin, 2005).

For discussion of the relationship of extent of activation to proficiency in the two languages, see Wartenburger et al. (2003, pp. 167-168). For a discussion of the extent of activation pattern changes with aging, see Park and Gutchess (2005, pp. 237-238).

AoA and Proficiency: ERP Studies. Broadly speaking, the ERP literature relating to the When of language processing is 
consistent with the fMRI and PET literature that speaks to the Where question; that is, the timing components of high-proficient L2 use are by and large similar to those of L1 use, even when acquisition of L2 was begun at age 12 or later (e.g., Hahne, 2001; Hahne \& Friederici, 2001; Ojima, Nakata, \& Kakigi, 2005; Proverbio, Cok, \& Zani, 2002; Stowe \& Sabourin, 2005). From the ERP studies, as with imaging studies, it appears that there is general support for the "convergence hypothesis" articulated by Green (2005), which states that as L2 proficiency increases, the processing profile in the L2 becomes more similar to that of native L1 use.

Recent research suggests that the similarities appear earlier in the course of adult L2 learning than had been previously thought; for example, McLaughlin, Osterhout, and Kim (2004) found P600 effects for syntactic violations after just 4 months of L2 learning, and Osterhout, McLaughlin, Kim, and Inoue (2004) demonstrated nativelike word versus pseudo-word N400 effects after only $14 \mathrm{hr}$ of instruction. The corresponding behavioral results for the subjects were not nativelike, suggesting that the amount of L2 learning taking place might be understated in behavioral data (see also Indefrey, Hellwig, Davidson, \& Gullberg, 2005; Mueller, Hahne, Fujii, \& Friederici, 2005).

On the other hand, the study by Sabourin (2003) suggests that behavioral measures might overstate similarities, whereas ERP might pick up on differences, at least among mid-proficiency L2 learners of different L1 backgrounds. Subjects were late learners ( $>12$ years AoE) of Dutch from German, Romance, and English native-language backgrounds. On grammaticality judgments of verb feature agreement, all three learner groups performed at about 90\% accuracy (native controls' accuracy = 97.4\%). However, the groups differed in terms of ERP signals recorded as the judgments were being made. The German group showed roughly nativelike N400 and P600 responses, whereas the Romance and English groups displayed no early negativity and their P600 was delayed and smaller relative to native control data. 


\section{The Aging Brain}

The next descriptive component in our consideration of age and L2A consists of facts about the aging brain, with which explanatory accounts of age-related differences in ultimate attainment must be compatible. Neurocognitive features of aging are amenable to investigation at various organizational and analytic levels. Those relevant to language learning and use include the functional/processing level (lexical encoding and retrieval, processing speed and depth, concatenation and coordination of grammatical units in real time, etc.), the functional/learning level (Hebbian learning, declarative memory and procedural memory, etc.), the brain structure level (hippocampus, striatum, etc.), and the cellular level (neurotransmission, regional volumetric decline, neurogenesis, etc.). The basic consideration is the degree and locus of age effects at these various levels of analysis.

\section{L2 and Cognitive Aging}

From the work of Bäckman and colleagues (e.g., Bäckman, Small, \& Wahlin, 2001), Park (e.g., Park, 2000), Salthouse (e.g., Salthouse, 1996), and others, we have come to recognize several general patterns in cognitive aging. In tasks that tap working memory and episodic memory, there is an observed performance decline over age, starting in young adulthood. Declines in associative memory and incremental learning also appear to begin in young adulthood. On tasks involving priming, recent memory, procedural memory, and semantic memory, age-related effects, when observed, are comparatively mild (Craik, 2000, pp. 78ff). Age effects are also comparatively mild for implicit memory tasks versus explicit memory tasks relating to lexical recall (Park, pp. 7-8).

Researchers have identified three principal components of cognitive aging (Park, 2000): decreases in processing speed, deficits in working memory, and decreases in suppression (i.e., the ability to focus attention on relevant material that some link 
to working memory; see also Rogers, 2000). Each of these abilities is involved in some stages of L2 acquisition and routinely in language use (L1 and L2). ${ }^{6}$ With increasing age, both L1 and L2 use are affected via declines in these areas of language processing. In L2 use, age effects in these domains are likely to be more pronounced than in the L1 case, due to a relatively low degree of automaticity in L2 processing (Segalowitz \& Hulstijn, 2005).

On tasks where speed and efficiency demands are made and when relatively new information is involved, two features of the age gradient stand out. First, the onset of performance decline begins in early adulthood (around age 20). Second, the decline across the adult life span is generally linear and, in all cases, continuous (Bäckman \& Farde, 2005, p. 68). Note that within the general trends in cognitive performance, there is a range of variation among individuals. These should play out in L2A as interindividual differences in ultimate attainment.

\section{Age, Brain Volume, and L2}

In this subsection we speculatively explore the possibility of a connection between brain volume decreases in aging and declines in L2 acquisition and processing. The volumetric decreases are known to begin in the twenties or later, indicating that if there were a link between brain volume and L2A, it would clearly be biological in nature, but not maturational.

In vivo studies using magnetic resonance imaging (MRI) reveal that, as a general rule, brain volume decreases with advancing age (see Raz, 2005, for a review). The degree of shrinkage varies from brain structure to brain structure, as do the details of timing of the onset of decline. In all cases surveyed, the declines, once begun, are typically linear and are consistently continuous, with no leveling off at the end.

Starting at the coarsest level of investigation, in vivo studies reveal that gray matter volume declines in a linear fashion beginning in childhood (e.g., Pfefferbaum et al., 1994; Courchesne et al., 2000). (Postmortem studies reveal a slightly different 
trajectory; see Miller, Alston, \& Corsellis, 1980; cited in Raz, 2005.) In contrast, white matter volume enjoys a linear increase until the early twenties. An ensuing plateau continues into the sixties, after which there is a linear decline into old age. The inverted $U$ shape for white matter volume over age has been replicated in many but not all studies. Declines are minimized in healthy subjects and are heightened in subjects with cardiovascular disease (Raz, p. 22).

Looking now at specific regions of interest, the question driving a great deal of research is whether the volumes of some areas of the brain are more affected by age than others. The answer to this question is not straightforward, as differing results are obtained by different measurement techniques and in longitudinal and cross-sectional studies, with the latter typically underestimating the amount of shrinkage. However, a reasonably clear picture of age-related declines in regional brain volumes was offered by Raz (2005) in his survey of relevant studies. Results of cross-sectional studies reveal that the sites most affected by age are the prefrontal cortex, the putamen, the caudate nucleus, the hippocampus, and the temporal cortex. In longitudinal studies, we find that the four areas most susceptible to volumetric declines are the entorhinal cortex, the hippocampus, the caudate nucleus, and the frontal lobe, all with $\geq 1 \%$ annual declines.

In addition to these data, consider the results of the Raz et al. (2003) study of 53 healthy adults between the ages of 20 and 77 years. Focusing on the striatum, the researchers found that the caudate nucleus volume declined at $.83 \%$ per year, the putamen at $.73 \%$ per year, and the globus pallidus at $.51 \%$ per year. The shrinkage began in young adulthood. The observed declines were also linear; that is, the same rate of decline was observed for younger and older subjects. These volume declines in the striatal region go hand in hand with dopamine declines in this area (see next subsection).

Most studies, however, do not reveal the epochs at which declines begin and at which the slopes are most dramatic. However, 
Raz (2005) sifted through the relevant studies to come to a few generalizations about timing and geometry of declines. First, volumes of the caudate nucleus, cerebellum, and cortical structures decline in a linear fashion that starts in adolescence and continues throughout the life span. Second, the entorhinal cortex and hippocampus appear to incur a greater annual shrinkage than other areas of the brain. These declines tend to begin in middle age to old age in the case of the hippocampus, and only in older age for the entorhinal cortex.

Whereas the relationship between brain volume and aging is typically linear and unbounded (bearing in mind that the age of onset of declines might vary from structure to structure), the relationship between brain volume and cognitive declines is apparently not linear in many cases. It has been suggested that cognitive deficits start to be expressed after structural deterioration reaches a certain threshold, but not before (Raz, 2000, p. 65). Consequently, it is challenging to connect regional morphological changes to specific cognitive deficits that might be related to L2 acquisition and processing. (Additional difficulties in making such connections arise from concerns relating to sampling, measurement, and methodological differences between studies, and interpretation of behavioral and imaging data.)

Two studies illustrate the challenges posed by this type of research. Golomb et al. (1994) found that declines in hippocampal volume predicted performance decrements on delayed declarative memory tasks (e.g., list recall, paragraph recall, and paired associates). On the other hand, Reuter-Lorenz (2000, pp. 101ff) observed that volumetric declines in the medial/temporal areas were not clearly paralleled by performance declines in episodic/associative (declarative) memory. ${ }^{7}$ Given the present state of research, the fairest observation to be made is that neural resources, for which regional brain volume is a proxy, are reasonably good predictors of performance subserved by certain brain areas, but not others. (See related discussion in the following section.) 
Age, Dopamine Systems, and L2A

The role of the nigrostriatal dopamine (DA) system in efficient motoric function is well known. In addition, DA appears to be involved in certain higher order cognitive functions, many of which are implicated in language learning and language processing, such as attention, motoric sequencing, and working memory (for a review, see Bäckman \& Farde, 2005).

Schumann (1997, 2001) and colleagues (Schumann et al., 2004) have argued that DA is involved in basal ganglia functions in L2A, some of which are implicated in motivation to learn and learning reinforcement. These mechanisms are thought to contribute to proceduralization (i.e., the creation and strengthening of linguistic rules; Lee, 2004, pp. 66-67). The results of the study by Teichmann et al. (2005) of Huntington disease patients reinforce the notion that the striatum is involved in the processing of rules as opposed to words. Crosson et al. (2003) argued for a role of the basal ganglia (BG) in a variety of language production processes at the levels of syntax, lexicon, and phonology. For additional studies of BG involvement in language processing, see Friederici and Kotz (2003), Moro et al. (2001), Newman, Pancheva, Ozawa, Neville, and Ullman (2001), and Ullman (in press).

Dopamine is likewise considered essential to defossilization, an undoing of automatized nontargetlike linguistic performance (Lee, 2004, pp. 68-71). Arguably, similar DA-mediated processes are also involved in minimizing L1 influence; for example, one could envision the role of DA in suppressing and supplanting L1 routines in syntax (e.g., association of noun-first clausal sequences with subject-initial canonical word order, when in fact the L2's canonical word order is object-initial) and routines in phonology (e.g., the representation of aspirate and nonaspirate stops as allophones, as in English, when the L2 represents them as separate phonemes, as in Korean).

In humans, D1 and D2 receptors are distributed throughout the neocortex, and there is dense innervation in the caudate 
nucleus and putamen. Damage to the DA system in humans results in deficits in executive function, verbal fluency, and perceptual speed. In rodent and monkey studies, destruction of dopaminergic pathways in the limbic system produces memory impairments and attentional deficits. Lesioning these pathways in the subthalamic nucleus results in deficits in attention, executive function, and motor sequencing. Pharmacological interventions in humans show increased performance on tasks that measure information processing speed, discrimination, and working memory. Both D1 and D2 receptors appear to be implicated in working memory modulation. Models of DA function converge on the notion that DA facilitates switching between attentional targets both within and between neural networks, with the effect of enhancing the ratio of incoming neural signal to background noise. For a review of effects on cognition of agerelated changes in nigrostriatal DA, see Bäckman and Farde (2005).

Li, Lindenberger, and Sikström (2001) found that declines in $\mathrm{D} 2$ receptors begin in the early twenties and continue across the life span. These declines are observed not only in the BG but also in the hippocampal structures, frontal cortex, anterior cingulate cortex, and amygdala. Of particular interest is the suggestion by $\mathrm{Li}$ et al. (2001) that with increased age and DA loss, neural noise increases, resulting in less distinctive neural representations. This decrease is linked to age-related cognitive deficits across domains such as working memory and executive function (Bäckman \& Farde, 2005, p. 61).

A few PET studies have looked at age-related declines in DA markers and associated cognitive declines. A familiar pattern of results emerges from these studies: Declines begin in early twenties and continue linearly throughout the life span. A representative study is that of Volkow et al. (1998), who determined by PET the striatal D2 binding potential in adults aged 24-86 years. Behavioral measures included executive, motoric, and perceptual speed. D2 receptor binding decreased with advancing age in the caudate nucleus $(r=-.62)$ and putamen 
$(r=-.7)$; similar correlations were obtained between age and task performance.

Thus, with respect to the geometry and timing of the DA age gradient and in terms of the cognitive functions mediated by DA, it would appear that DA declines are a plausible mechanism (among others) underlying age effects in L2 acquisition and processing. A similar conclusion could apply to stress- and age-related increases in cortisol, which have been linked to hippocampal atrophy (Lupien et al., 1994, 1998). Also, with adjustments in the temporal and geometric features of the age-related declines, the same might be said of fluctuations in estrogen levels over age, as forms of this hormone are known to mediate verbal memory, production, and processing (e.g., Kimura, 1995; Resnick $\&$ Maki, 2001). As was the case with respect to brain volume declines, the possible linkage to L2A of changes in dopamine, estrogen/testosterone, and acetylcholine metabolism (e.g., Freeman \& Gibson, 1988) is understood to be biological in nature, but given that the changes do not begin until adulthood, a maturational explanation is ruled out.

\section{Summary}

In a nutshell, what do studies of the aging brain reveal about L2 acquisition and processing? From the cognitive literature, we learn that the associative memory and incremental learning elements of language learning are steadily compromised by age, as are the working memory and processing speed components of language processing and production. It appears that these declines are linear and that they begin in early adulthood and continue throughout the life span.

Second language use, at least among non-L2-dominants, is less automatic and less efficient than L1 use. As increasing demands are made on a finite-capacity functional system, performance declines are to be expected. For this reason, processing deficits are likely to show up earlier and to be more pronounced in typical L2 use than in L1 use. 
For some areas of the brain, we see some evidence of linkages between age-related morphological changes and the cognitive processes mediating L2 learning, production, and processing; for example, age-related declines in working memory, attention, and speed of processing appear to be roughly correlated with volumetric declines in the frontal lobe and prefrontal cortex, the latter area being particularly susceptible to the effects of aging. A somewhat stronger case can be made for the relation of agerelated dopamine declines to a variety of cognitive deficits that could undermine L2 processing and acquisition, as the research findings appear to be more straightforwardly interpretable than those associated with brain volume studies.

As for the timing of changes in the aging brain, none of the evidence from the cognitive, brain volume, or dopamine literature is consistent with a maturational account because the observed declines commence after the end of maturation. With respect to the geometry of declines, the literature in all three areas generally indicates linear declines. However, it has been suggested that for some brain regions, the actual expression of functional deficits does not begin at the onset of volumetric changes, but at a point later in life when a theorized threshold has been crossed. ${ }^{8} \mathrm{Ar}-$ guably, such a suggestion could extend to the connection between neurobiological/neurochemical/neuroanatomical states and cognitive processes in general.

Finally, it should be emphasized that in this section, we have mentioned only a few of the well-studied neural sources of agerelated cognitive decline. For a comprehensive overview of the cognitive neuroscience of aging, see Cabeza, Nyberg, and Park (2005).

\section{The Nature of Age Effects in L2A}

To conclude this overview, let us step back and reflect briefly on the sources of age effects in L2A. In the literature, we find a multiplicity of candidate causal mechanismsbiological and experiential—and mediating factors—endogenous 
and exogenous - that underlie age effects in L2A. Singleton (2005) saw no less than 14 versions of the Critical Period Hypothesis as it applies to L2A (CPH/L2A). Birdsong (1999) cited six major variants of the $\mathrm{CPH} / \mathrm{L} 2 \mathrm{~A}$ and pointed to numerous endogenous and exogenous factors that affect ultimate attainment in L2A. MacWhinney (2005b) identified 10 "concrete proposals" in the literature that relate AoA to ultimate L2A attainment, and to these were added two explanations for variability in L2A outcomes. The various hypothesized mechanisms relate to the biology of the species (in its neurobiological or neurocognitive dimensions), developmental aspects of cognition, L1 influence, use of the L1 and L2, and psycho-social/affective dimensions of individuals' personalities, including a person's motivation to learn, appear nativelike, or integrate into the L2 culture.

A summary and evaluation of these accounts would be impractical in the present context (for critical reviews, see Herschensohn, in press; Singleton \& Ryan, 2004). A brief commentary must suffice.

There is an understandable tendency in discussions of the underlying sources of age effects in L2 learning and processing to isolate a single mechanism or to focus on one type of mechanism. Yet, this practice often simplifies the phenomena in question and polarizes stances on an extremely textured set of issues. It is arguably more reasonable to take the initial position that the identified factors and mechanisms that are not at odds with empirical findings are each potentially at work in some fashion in L2A. Some might account for more variance than others, and individual differences in L2 attainment and processing are to be expected (Bowden, Sanz, \& Stafford, 2005; Dörnyei \& Skehan, 2003; Skehan, 1989). Some factors trump others; for example, it is pointless to invoke neurobiological capacities (or deficiencies) in the context of an individual who has no interest in passing for a native (Klein, 1995; Moyer, 2004; Piller, 2002).

Ongoing research in L2 acquisition must account not only for the typical decline in L2 attainment with age but also for the 
nativelikeness that late learners are manifestly capable of. To do so adequately will require clear-eyed and open-minded attempts to integrate biological, cognitive, experiential, linguistic, and affective dimensions of L2 learning and processing.

\section{Notes}

${ }^{1}$ Innately specified linguistic knowledge given by UG is posited to account for the apparent gap between learners' knowledge of linguistic structure and what they have been exposed to in the linguistic input (e.g., Chomsky, 1975). In late L2A, learners have access to fully developed linguistic representations in their L1. With this knowledge, supplemented by domain-general learning procedures such as inference and analogical patterning-and of course, L2 input-nativelikeness in at least some areas of the grammar is undeniably possible. Thus, not all nativelikeness is evidence for access to UG. For particular abstract linguistic features or structures, access to UG is inferred from evidence that L2 learners' knowledge could not have been attained by L2 input and domain-general cognition. For elaboration on this point, see Coopmans (this volume).

${ }^{2}$ These figures are expressed as absolute values because some experiments correlate AoA with numbers of errors or degree of foreign accent-thus resulting in positive correlation coefficients-whereas others correlate AoA with numbers of correct items or degree of nativelike accent-thus yielding negative correlations.

${ }^{3}$ The hypothesis of a critical period for L2A has been formulated by different researchers in different ways and invoking a variety of explanatory mechanisms; see the final section of this article as well as Birdsong (1999), Herschensohn (in press), Singleton (2005), and Singleton and Ryan (2004) for overviews.

${ }^{4}$ For their early-arriving subjects, DeKeyser (2000) and Patkowski (1990) found near-zero correlations of attainment and age. However, in both studies, the data for early arrivals did not constitute flat functions at ceiling, which would be consistent with a window of opportunity for full attainment.

${ }^{5}$ It is important to recognize that "L2-dominant" is not a homogeneous category. Like proficiency, dominance is a continuous construct. The degree to which a person is L2-dominant, as operationalized by performance on quantitative psycholinguistic measures such as reading speed or numbers of words extracted from L1 versus L2 speech amid background noise, varies from one individual to another. Dominance is also a relative construct; it is expressed, for example, as the proportion of words read per minute in the L2 and L1. L2 dominance does not always equate to nativelikeness. For a given L2-dominant, the number of words read per minute in the L2 might 
not necessarily fall in the range of reading speed of monolingual natives. Further, dominance is not to be confused with grammatical proficiency. The fact that a given bilingual is better at extracting signal from noise in a particular language does not necessarily mean that this person is highly proficient in that language. Finally, this section has concentrated on psycholinguistic definitions of dominance, as opposed to frequency of use or psycho-social identification with a given language. For discussion of various operationalizations of dominance, see Flege et al. (2002), Golato (1998), and Grosjean (1998).

${ }^{6}$ Among bilinguals, working memory might be involved in controlling the activation of the two languages (see Kroll \& Tokowicz, 2005; Michael \& Gollan, 2005), which might be tied to a general ability to suppress irrelevant information (see Anderson, 2003; Michael \& Gollan). Scores on tests of working memory in the L2 correlate with L2 proficiency (Stafford, 2005; see also Bowden et al., 2005). Thus, in the typical case of nonnativelike L2 proficiency, working memory capacities in the L2 should be inferior to those in the L1.

${ }^{7}$ Associative memory is essential to connectionist accounts of language acquisition and use and to the representation and processing of irregular forms under the words-and-rules approach (e.g., Pinker \& Ullman, 2002) in both L1 and L2 (Ullman, 2001).

${ }^{8}$ This review of the aging brain has not considered the relationship between neurocognitive processing resources that are affected by aging and the actual level of activation of neural tissue in the particular brain regions in question. For consideration of technical, empirical, and theoretical issues surrounding this question, see Park and Gutchess (2005).

\section{References}

Abutalebi, J., Cappa, S. F., \& Perani, D. (2005). What can functional neuroimaging tell us about the bilingual brain? In J. F. Kroll \& A. M. B. de Groot (Eds.), Handbook of bilingualism: Psycholinguistic approaches (pp. 497-515). New York: Oxford University Press.

Anderson, M. C. (2003). Rethinking interference theory: Executive control and the mechanisms of forgetting. Journal of Memory and Language, 49, 415-445.

Bäckman, L., \& Farde, L. (2005). The role of dopamine systems in cognitive aging. In R. Cabeza, L. Nyberg, \& D. Park (Eds.), Cognitive neuroscience of aging: Linking cognitive and cerebral aging (pp. 58-84). New York: Oxford University Press.

Bäckman, L., Small, B. J., \& Wahlin, Å. (2001). Aging and memory: Cognitive and biological perspectives. In J. E. Birren \& K. W. Schaie (Eds.), Handbook of the psychology of aging (5th ed., pp. 349-377). San Diego, CA: Academic Press. 
Balcom, P. (2003). Cross-linguistic influence of L2 English on middle constructions in L1 French. In V. Cook (Ed.), Effects of the second language on the first (pp. 168-192). Clevedon, UK: Multilingual Matters.

Bialystok, E., \& Hakuta, K. (1994). In other words: The science and psychology of second-language acquisition. New York: Basic Books.

Bialystok, E., \& Miller, B. (1999). The problem of age in second language acquisition: Influences from language, task, and structure. Bilingualism: Language and Cognition, 2, 127-145.

Birdsong, D. (1992). Ultimate attainment in second language acquisition. Language, 68, 706-755.

Birdsong, D. (1999). Introduction: Whys and why nots of the Critical Period Hypothesis. In D. Birdsong (Ed.), Second language acquisition and the Critical Period Hypothesis (pp. 1-22). Mahwah, NJ: Erlbaum.

Birdsong, D. (2003). Authenticité de prononciation en français L2 chez des apprenants tardifs anglophones: Analyses segmentales et globales. Acquisition et Interaction en Langue Étrangère, 18, 17-36.

Birdsong, D. (2004). Second language acquisition and ultimate attainment. In A. Davies \& C. Elder (Eds.), The handbook of applied linguistics (pp. 82-105). Malden, MA: Blackwell.

Birdsong, D. (2005). Interpreting age effects in second language acquisition. In J. F. Kroll \& A. M. B. de Groot (Eds.), Handbook of bilingualism: Psycholinguistic approaches (pp. 109-127). New York: Oxford University Press.

Birdsong, D., \& Molis, M. (2001). On the evidence for maturational effects in second language acquisition. Journal of Memory and Language, 44, $235-249$.

Bley-Vroman, R. (1989). What is the logical problem of foreign language learning? In S. Gass \& J. Schachter (Eds.), Linguistic perspectives on second language acquisition (pp. 41-68). Cambridge, UK: Cambridge University Press.

Bongaerts, T. (1999). Ultimate attainment in L2 pronunciation: The case of very advanced late learners. In D. Birdsong (Ed.), Second language acquisition and the critical period hypothesis (pp. 133-159). Mahwah, NJ: Erlbaum.

Bornstein, M. H. (1989). Sensitive periods in development: Structural characteristics and causal interpretations. Psychological Bulletin, 105, 179197.

Bowden, H. W., Sanz, C., \& Stafford, C. A. (2005). Individual differences: Age, sex, working memory, and prior knowledge. In C. Sanz (Ed.), Mind and context in adult second language acquisition: Methods, theory, and practice (pp. 105-140). Washington, DC: Georgetown University Press. 
Bradlow, A. R., Pisoni, D. B., Akahane-Yamada, R. A., \& Tohkura, Y. (1997). Training Japanese listeners to identify English /r/ and /l/: IV. Some effects of perceptual learning on speech production. Journal of the Acoustical Society of America, 101, 2299-2310.

Cabeza, R., Nyberg, L., \& Park, D. (2005). Cognitive neuroscience of aging: Linking cognitive and cerebral aging. New York: Oxford University Press.

Chee, M. W. L., Hon, N., Lee, H. L., \& Soon, C. S. (2001). Relative language proficiency modulates BOLD signal change when bilinguals perform semantic judgments. NeuroImage, 13, 1155-1163.

Chee, M. W. L., Tan, E. W. L., \& Thiel, T. (1999). Mandarin and English single word processing studied with functional magnetic resonance imaging. Journal of Neuroscience, 19, 3050-3056.

Chee, M. W. L., Weekes, B., Lee, K. M., Soon, C. S., Schreiber, A., Hoon, J. J., et al. (2000). Overlap and dissociation of semantic processing of Chinese characters, English words, and pictures: Evidence from fMRI. NeuroImage, 12, 392-403.

Chomsky, N. (1975). Reflections on language. New York: Pantheon.

Clahsen, H., \& Felser, C. (2006). Grammatical processing in language learners. Applied Psycholinguistics, 27, 3-42.

Cook, V. (2002). Background to the L2 user. In V. Cook (Ed.), Portraits of the L2 user. Clevedon, UK: Multilingual Matters.

Cook, V., Iarossi, E., Stellakis, N., \& Tokumaru, Y. (2003). Effects of the L2 on the syntactic processing of the L1. In V. Cook (Ed.), Effects of the second language on the first (pp. 193-213). Clevedon, UK: Multilingual Matters.

Courchesne, E., Chisum, H. J., Townsend, J., Cowles, A., Covington, J., Egaas, B., et al. (2000). Normal brain development and aging: Quantitative analysis at in vivo MR imaging in healthy volunteers. Radiology, $216,672-682$.

Craik, F. I. M. (2000). Age-related changes in human memory. In D. C. Park \& N. Schwarz (Eds.), Cognitive aging: A primer (pp. 75-92). Philadelphia: Psychology Press.

Cranshaw, A. (1997). A study of Anglophone native and near-native linguistic and metalinguistic performance. Unpublished doctoral dissertation, Université de Montréal, Montréal, Canada.

Crosson, B., Benefield, H., Cato, M. A., Sadek, J. R., Moore, A. B., Wierenga, C. E., et al. (2003). Left and right basal ganglia activity during language generation: Contributions to lexical, semantic and phonological processes. Journal of the International Neuropsychological Society, 9, 1061-1077.

Darcy, I., Peperkamp, S., \& Dupoux, E. (in press). Plasticity in compensation for phonological variation: The case of late second language learners. LabPhon 9. 
De Bleser, R., Dupont, P., Postler, J., Bormans, G., Speelman, D., Mortelmans, L., et al. (2003). The organization of the bilingual lexicon: A PET study. Journal of Neurolinguistics, 16, 439-456.

Dehaene, D., Dupoux, E., Mehler, J., Cohen, L., Paulesu, E., Perani, D., et al. (1997). Anatomical variability in the cortical representation of first and second languages. NeuroReport, 8, 3809-3815.

DeKeyser, R. M. (2000). The robustness of critical period effects in second language acquisition. Studies in Second Language Acquisition, 22, 499533.

DeKeyser, R., \& Larson-Hall, J. (2005). What does the critical period really mean? In J. F. Kroll \& A. M. B. de Groot (Eds.), Handbook of bilingualism: Psycholinguistic approaches (pp. 88-108). New York: Oxford University Press.

Ding, G., Perry, C., Peng, D., Ma, L., Li, D., Xu, S., et al. (2003). Neural mechanisms underlying semantic and orthographic processing in ChineseEnglish bilinguals. NeuroReport, 14, 1557-1562.

Dörnyei, Z., \& Skehan, P. (2003). Individual differences in second language learning. In C. J. Doughty \& M. H. Long (Eds.), The handbook of second language acquisition (pp. 589-630). Malden, MA: Blackwell.

Doughty, C. J. (2003). Instructed SLA: Constraints, compensation, and enhancement. In C. J. Doughty \& M. H. Long (Eds.), The handbook of second language acquisition (pp. 256-310). Malden, MA: Blackwell.

Dupoux, E., \& Peperkamp, S. (2002). Fossil markers of language development: Phonological "deafnesses" in adult speech processing. In J. Durand \& B. Laks (Eds.), Phonetics, phonology, and cognition (pp. 168-190). Oxford: Oxford University Press.

Dussias, P. E. (2004). Syntactic ambiguity resolution in L2 learners: Some effects of bilinguality on L1 and L2 processing strategies. Studies in Second Language Acquisition, 25, 529-557.

Flege, J. (2002). No perfect bilinguals. In A. James \& J. Leather (Eds.), New sounds 2000: Proceedings of the Fourth International Symposium on the Acquisition of Second-Language Speech (pp. 132-141). University of Klagenfurt.

Flege, J. E., \& Hillenbrand, J. (1984). Limits on phonetic accuracy in foreign language speech production. Journal of the Acoustical Society of America, 76, 708-721.

Flege, J. E., MacKay, I. R. A., \& Piske, T. (2002). Assessing bilingual dominance. Applied Psycholinguistics, 23, 567-598.

Flege, J. E., Yeni-Komshian, G. H., \& Liu, S. (1999). Age constraints on second-language acquisition. Journal of Memory and Language, 41, 78104. 
Freeman, G. B., \& Gibson, G. E. (1988). Dopamine, acetylcholine, and glutamate interactions in aging. Behavioral and neurochemical correlates. Annals of the New York Academy of Sciences, 515, 191-202.

Frenck-Mestre, C. (2005). Ambiguities and anomalies: What can eye movements and event-related potentials reveal about second language sentence processing? In J. F. Kroll \& A. M. B. de Groot (Eds.), Handbook of bilingualism: Psycholinguistic approaches (pp. 268-281). New York: Oxford University Press.

Friederici, A. D., \& Kotz, S. A. (2003). The brain basis of syntactic processes: Functional imaging and lesion studies. NeuroImage, 20(Suppl. 1), S8S17.

Golato, P. (1998). Syllabification processes among French-English bilinguals: A further study of the limits of bilingualism. Unpublished doctoral dissertation, University of Texas-Austin.

Golomb, J., Kluger, A., de Leon, M. J., Ferris, S. H., Convit, A., Mittelman, M., et al. (1994). Hippocampal formation size in normal human aging: A correlate of delayed secondary memory performance. Learning and Memory, $1,45-54$.

Green, D. W. (2005). The neurocognition of recovery patterns in bilingual aphasics. In J. F. Kroll \& A. M. B. de Groot (Eds.), Handbook of bilingualism: Psycholinguistic approaches (pp. 516-530). New York: Oxford University Press.

Grosjean, F. (1989). Neurolinguists, beware! The bilingual is not two monolinguals in one person. Brain and Language, 36, 3-15.

Grosjean, F. (1998). Studying bilinguals: Methodological and conceptual issues. Bilingualism: Language and Cognition, 1, 131-149.

Hahne, A. (2001). What's different in second-language processing? Evidence from event-related brain potentials. Journal of Psycholinguistic Research, $30,251-256$.

Hahne, A., \& Friederici, A. (2001). Processing a second language: Late learners' comprehension mechanisms as revealed by event-related brain potentials. Bilingualism: Language and Cognition, 4, 123-141.

Herschensohn, J. (in press). Language development and age. Cambridge: Cambridge University Press.

Hyltenstam, K., \& Abrahamsson, N. (2000). Who can become native-like in a second language? All, some, or none? On the maturational constraints controversy in second language acquisition. Studia Linguistica, 54, 150 166.

Hyltenstam, K., \& Abrahamsson, N. (2003). Maturational constraints in SLA. In C. J. Doughty \& M. H. Long (Eds.), The handbook of second language acquisition (pp. 539-588). Malden, MA: Blackwell. 
Indefrey, P., Hellwig, F., Davidson, D., \& Gullberg, M. (2005). Nativelike hemodynamic responses during sentence comprehension after six months of learning a new language. Poster presented at the 11th Annual Meeting of the Organization for Human Brain Mapping, Toronto.

Ioup, G., Boustagui, E., El Tigi, M., \& Moselle, M. (1994). Reexamining the critical period hypothesis: A case study of successful adult SLA in a naturalistic environment. Studies in Second Language Acquisition, 16, 7398.

Johnson, J. S., \& Newport, E. L. (1989). Critical period effects in second language learning: The influence of maturational state on the acquisition of English as a second language. Cognitive Psychology, 21, 60-99.

Kim, K. H. S., Relkin, N. R., Lee, K.-M., \& Hirsch, J. (1997). Distinct cortical areas associated with native and second languages. Nature, 388, 171174.

Kimura, D. (1995). Estrogen replacement therapy may protect against intellectual decline in postmenopausal women. Hormones \& Behavior, 29, $312-321$.

Klein, D., Milner, B., Zatorre, R., Meyer, E., \& Evans, A. (1995). The neural substrates underlying word generation: A bilingual functional-imaging study. Proceedings of the National Academy of Sciences of the United States of America, 92, 2899-2903.

Klein, D., Zatorre, R. J., Milner, B., Meyer, E., \& Evans, A. C. (1994). Left putaminal activation when speaking a second language: Evidence from PET. NeuroReport, 5, 2295-2297.

Klein, W. (1995). Language acquisition at different ages. In D. Magnusson (Ed.), The lifespan development of individuals: Behavioral, neurobiological, and psychosocial perspectives. A synthesis (pp. 244-264). Cambridge: Cambridge University Press.

Knudsen, E. I. (2004). Sensitive periods in the development of the brain and behavior. Journal of Cognitive Neuroscience, 16, 1412-1425.

Kroll, J. F., \& Tokowicz, N. (2005). Models of bilingual representation and processing: Looking back and to the future. In J. F. Kroll \& A. M. B. de Groot (Eds.), Handbook of bilingualism: Psycholinguistic approaches (pp. 531-553). New York: Oxford University Press.

Kuhl, P. K. (2000). A new view of language acquisition. Proceedings of the National Academy of Sciences of the United States of America, 97, 11,85011,857 .

Larsen-Freeman, D. (2005). Second language acquisition and the issue of fossilization: There is no end, and there is no state. In Z.-H. Han \& T. Odlin, Studies of fossilization in second language acquisition (pp. 189200). Clevedon, UK: Multilingual Matters. 
Laufer, B. (2003). The influence of L2 on L1 collocational knowledge and on L1 lexical diversity in free written expression. In V. Cook (Ed.), Effects of the second language on the first (pp. 19-31). Clevedon, UK: Multilingual Matters.

Lee, N. (2004). The neurobiology of procedural memory. In J. H. Schumann, S. E. Crowell, N. E. Jones, N. Lee, S. A. Schuchert, \& L. A. Wood, The neurobiology of learning: Perspectives from second language acquisition (pp. 43-73). Mahwah, NJ: Erlbaum.

Lenneberg, E. H. (1967). Biological foundations of language. New York: Wiley.

Li, S.-C., Lindenberger, U., \& Sikström, S. (2001). Aging cognition: From neuromodulation to representation. Trends in Cognitive Sciences, 5, 479486.

Long, M. H. (1990). Maturational constraints on language development. Studies in Second Language Acquisition, 12, 251-285.

Lupien, S., De Leon, M., De Santi, S., Convit, A., Tarshish, C., Nair, N. P. V., et al. (1998). Longitudinal increase in cortisol during human aging predicts hippocampal atrophy and memory deficits. Nature Neuroscience, 1 , 69-73.

Lupien, S., Lecours, A. R., Lussier, I., Schwartz, G., Nair, N. P. V., \& Meaney, M. J. (1994). Basal cortisol levels and cognitive deficits in human aging. Journal of Neuroscience, 14, 2893-2903.

Mack, M., Bott, S., \& Boronat, C. B. (1995). Mother, I'd rather do it myself, maybe: An analysis of voice-onset time produced by early French-English bilinguals. IDEAL, 8, 23-55.

MacWhinney, B. (2005a). A unified model of language acquisition. In J. F. Kroll \& A. M. B. de Groot (Eds.), Handbook of bilingualism: Psycholinguistic approaches (pp. 49-67). New York: Oxford University Press.

MacWhinney, B. (2005b). Emergent fossilization. In Z.-H. Han \& T. Odlin, Studies of fossilization in second language acquisition (pp. 134-156). Clevedon, UK: Multilingual Matters.

Marinova-Todd, S. (2003). Comprehensive analysis of ultimate attainment in adult second language acquisition. Unpublished doctoral dissertation, Harvard University.

Marinova-Todd, S. H., Marshall, D. B., \& Snow, C. E. (2000). Three misconceptions about age and L2 learning. TESOL Quarterly, 34, 934.

McCandliss, B. D., Fiez, J. A., Protopapas, A., Conway, M., \& McClelland, J. L. (2002). Success and failure in teaching the [r]-[1] contrast to Japanese adults: Predictions of a Hebbian model of plasticity and stabilization in 
spoken language perception. Cognitive, Affective and Behavioral Neuroscience, 2, 89-108.

McClelland, J. L., Fiez, J. A., \& McCandliss, B. D. (2002). Teaching the /r/-/l/ discrimination to Japanese adults: Behavioral and neural aspects. Physiology \& Behavior, 77, 657-662.

McLaughlin, J., Osterhout, L., \& Kim, A. (2004). Neural correlates of secondlanguage word learning: Minimal instruction produces rapid change. $\mathrm{Na}$ ture Neuroscience, 7, 703-704.

Michael, E. B., \& Gollan, T. H. (2005). Being and becoming bilingual: Individual differences and consequences for language production. In J. F. Kroll \& A. M. B. de Groot (Eds.), Handbook of bilingualism: Psycholinguistic approaches (pp. 497-515). New York: Oxford University Press.

Miller, A. K., Alston, R. L., \& Corsellis, J. A. (1980). Variation with age in the volumes of grey and white matter in the cerebral hemispheres of man: Measurements with an image analyser. Neuropathology and Applied Neurobiology, 6, 119-132.

Moro, A., Tettamanti, M., Perani, D., Donati, C., Cappa, S. F., \& Fazio, F. (2001). Syntax and the brain: Disentangling grammar by selective anomalies. NeuroImage, 13, 110-118.

Moyer, A. (1999). Ultimate attainment in L2 phonology: The critical factors of age, motivation and instruction. Studies in Second Language Acquisition, 21, 81-108.

Moyer, A. (2004). Age, accent and experience in second language acquisition. Clevedon, UK: Multilingual Matters.

Mueller, J. L., Hahne, A., Fujii, Y., \& Friederici, A. D. (2005). Native and nonnative speakers' processing of a miniature version of Japanese as revealed by ERPs. Journal of Cognitive Neuroscience, 17, 1229-1244.

Newman, A. J., Pancheva, R., Ozawa, K., Neville, H. J., \& Ullman, M. T. (2001). An event-related fMRI study of syntactic and semantic violations. Journal of Psycholinguistic Research, 30, 339-364.

Ojima, S., Nakata, H., \& Kakigi, R. (2005). An ERP study of second language learning after childhood: Effects of proficiency. Journal of Cognitive Neuroscience, 17, 1212-1228.

Osterhout, L., McLaughlin, J., Kim, A., \& Inoue, K. (2004). Sentences in the brain: Event-related potentials as real-time reflections of sentence comprehension and language learning. In M. Carreiras \& C. Clifton, Jr. (Eds.), The on-line study of sentence comprehension: Eyetracking, ERP, and beyond. Philadelphia: Psychology Press.

Pallier, C., Dehaene, S., Poline, J.-B., LeBihan, D., Argenti, A.-M., Dupoux, E., et al. (2003). Brain imaging of language plasticity in adopted adults: Can a second language replace the first? Cerebral Cortex, 13, 155-161. 
Papadopoulou, D., \& Clahsen, H. (2004). Parsing strategies in L1 and L2 sentence processing: A study of relative clause attachment in Greek. Studies in Second Language Acquisition, 25, 501-528.

Paradis, M. (2004). A neurolinguistic theory of bilingualism. Amsterdam: Benjamins.

Paradis, M. (2005). Introduction to Part IV: Aspects and implications of bilingualism. In J. F. Kroll \& A. M. B. de Groot (Eds.), Handbook of bilingualism: Psycholinguistic approaches (pp. 411-415). New York: Oxford University Press.

Park, D. C. (2000). The basic mechanisms accounting for age-related decline in cognitive function. In D. C. Park \& N. Schwarz (Eds.), Cognitive aging: A primer (pp. 3-21). Philadelphia: Psychology Press.

Park, D. C., \& Gutchess, A. H. (2005). Long-term memory and aging: A cognitive neuroscience perspective. In R. Cabeza, L. Nyberg, \& D. Park (Eds.), Cognitive neuroscience of aging: Linking cognitive and cerebral aging (pp. 218-245). New York: Oxford University Press.

Patkowski, M. S. (1990). Age and accent in a second language: A reply to James Emil Flege. Applied Linguistics, 11, 73-89.

Perani, D., Dehaene, S., Grassi, F., Cohen, L., Cappa, S. F., Dupoux, E., et al. (1996). Brain processing of native and foreign languages. NeuroReport, 7, 2439-2444.

Perani, D., Paulesu, E., Sebastian-Galles, N., Dupoux, E., Dehaene, S., Bettinardi, V., et al. (1998). The bilingual brain: Proficiency and age of acquisition of the second language. Brain, 121, 1841-1852.

Pfefferbaum, A., Mathalon, D. H., Sullivan, E. V., Rawles, J. M., Zipursky, R. B., \& Lim, K. O. (1994). A quantitative magnetic resonance imaging study of changes in brain morphology from infancy to late adulthood. Archives of Neurology, 51, 874-887.

Pienemann, M., Di Biase, B., Kawaguchi, S., \& Hakansson, G. (2005). Processing constraints on L1 transfer. In J. F. Kroll \& A. M. B. de Groot (Eds.), Handbook of bilingualism: Psycholinguistic approaches (pp. 128153). New York: Oxford University Press.

Piller, I. (2002). Passing for a native speaker: Identity and success in second language learning. Journal of Sociolinguistics, 6, 179-206.

Pinker, S. (1994). The language instinct: How the mind creates language. New York: Morrow.

Pinker, S., \& Ullman, M. (2002). The past and future of the past tense. Trends in Cognitive Sciences, 6, 456-463.

Proverbio, A. M., Cok, B., \& Zani, A. (2002). Electrophysiological measures of language processing in bilinguals. Journal of Cognitive Neuroscience, $14,994-1017$. 
Raz, N. (2000). Aging of the brain and its impact on cognitive performance: Integration of structural and functional findings. In F. I. M. Craik \& T. A. Salthouse (Eds.), The handbook of aging and cognition (2nd ed., pp. 1-90). Mahwah, NJ: Erlbaum.

Raz, N. (2005). The aging brain observed in vivo: Differential changes and their modifiers. In R. Cabeza, L. Nyberg, \& D. Park (Eds.), Cognitive neuroscience of aging: Linking cognitive and cerebral aging (pp. 19-57). New York: Oxford University Press.

Raz, N., Rodrigue, K. M., Kennedy, K. M., Head, D., Gunning-Dixon, F. M., \& Acker, J. D. (2003). Differential aging of the human striatum: Longitudinal evidence. American Journal of Neuroradiology, 24, 18491856.

Resnick, S. M., \& Maki, P. M. (2001). Effects of hormone replacement therapy on cognitive and brain aging. Annals of the New York Academy of Sciences, 949, 203-214.

Reuter-Lorenz, P. A. (2000). Cognitive neuropsychology of the aging brain. In D. C. Park \& N. Schwarz (Eds.), Cognitive aging: A primer (pp. 93-114). Philadelphia: Psychology Press.

Rogers, W. A. (2000). Attention and aging. In D. C. Park \& N. Schwarz (Eds.), Cognitive aging: A primer (pp. 57-73). Philadelphia: Psychology Press.

Sabourin, L. (2003). Grammatical gender and second language processing: An ERP study. PhD dissertation, University of Groningen, The Netherlands.

Salthouse, T. A. (1996). Constraints on theories of cognitive aging. Psychonomic Bulletin \& Review, 3, 287-299.

Schaie, K. W. (1994). Developmental designs revisited. In S. H. Cohen \& H. W. Reese (Eds.), Life-span developmental psychology: Methodological considerations (pp. 45-64). Hillsdale, NJ: Erlbaum.

Schumann, J. H. (1997). The neurobiology of affect in language. Oxford: Blackwell.

Schumann, J. H. (2001). Appraisal psychology, neurobiology, and language. Annual Review of Applied Linguistics, 21, 23-42.

Schumann, J. H., Crowell, S. E., Jones, N. E., Lee, N., Schuchert, S. A., \& Wood, L. A. (2004). The neurobiology of learning: Perspectives from second language acquisition. Mahwah, NJ: Erlbaum.

Scovel, T. (1988). A time to speak: A psycholinguistic inquiry into the critical period for human speech. Rowley, MA: Newbury House.

Segalowitz, N., \& Hulstijn, J. (2005). Automaticity in bilingualism and second language learning. In J. F. Kroll \& A. M. B. de Groot (Eds.), Handbook of bilingualism: Psycholinguistic approaches (pp. 371-388). New York: Oxford University Press. 
Seliger, H. W. (1978). Implications of a multiple critical periods hypothesis for second language learning. In W. Ritchie (Ed.), Second language acquisition research: Issues and implications (pp. 11-19). New York: Academic Press.

Selinker, L. (1972). Interlanguage. International Review of Applied Linguistics, 10, 209-231.

Singleton, D. (2005). The Critical Period Hypothesis: A coat of many colours. International Review of Applied Linguistics, 43, 269-286.

Singleton, D., \& Ryan, L. (2004). Language acquisition: The age factor (2nd ed.). Clevedon, UK: Multilingual Matters.

Skehan, P. (1989). Individual differences in second-language learning. London: Edward Arnold.

Stafford, C. A. (2005). Bilingualism, cognitive capacity and age: A computerbased study in L3 processing. Unpublished doctoral dissertation, Georgetown University.

Stowe, L. A., \& Sabourin, L. (2005). Imaging the processing of a second language: Effects of maturation and proficiency on the neural processes involved. International Review of Applied Linguistics, 43, 329-354.

Takagi, N. (2002). The limits of training Japanese listeners to identify / $\mathrm{r} /$ and //: Eight case studies. Journal of the Acoustical Society of America, 111, 2887-2896.

Teichman, M., Dupoux, E., Kouider, S., Brugieres, J.-P., Boissé, M.-F., Baudic, S., et al. (2005). The Role of the striatum in rule application: The model of Huntington's disease at early stage. Brain, 128, 1155-1167.

Ullman, M. T. (2001). The neural basis of lexicon and grammar in first and second language: The declarative/procedural model. Bilingualism: Learning and Cognition, 4, 105-122.

Ullman, M. T. (in press). Is Broca's area part of a basal ganglia thalamocortical circuit? Cortex.

Van Hell, J. G., \& Dijkstra, T. (2002). Foreign language knowledge can influence native language performance in exclusively native contexts. Psychonomic Bulletin \& Review, 9, 780-789.

Ventureyra, V. A. (2005). A la recherche de la langue perdue: Étude de l'attrition de la première langue chez des Coréens adoptés en France. Unpublished doctoral dissertation, Ecole des Hautes Etudes en Sciences Sociales, Paris.

Volkow, N. D., Wang, G.-J., Fowler, J. S., Ding, Y.-S., Gur, R., Gatley, S. J., et al. (1998). Parallel loss of pre and postsynaptic dopamine markers in normal aging. Annals of Neurology, 44, 143-147.

Wartenburger, I., Heekeren, H. R., Abutalebi, J., Cappa, S. F., Villringer, A., \& Perani, D. P. (2003). Early setting of grammatical processing in the bilingual brain. Neuron, 37, 159-170. 
Weinert, F. E., \& Perner, J. (1996). Cognitive development. In D. Magnusson (Ed.), The lifespan development of individuals: Behavioral, neurobiological, and psychosocial perspectives: A synthesis (pp. 207-222). Cambridge: Cambridge University Press.

White, L. (2003). Fossilization in steady state L2 grammars: Persistent problems with inflectional morphology. Bilingualism: Language and Cognition, 6, 128-141.

Xue, G., Dong, Q., Jin, Z., Zhang, L., \& Wang, Y. (2004). An fMRI study with semantic access in low proficiency second language learners. NeuroReport, 15, 791-796. 